(C2007 IEEE. Personal use of this material is permitted. However, permission to reprint/republish this material for advertising or promotional purposes or for creating new collective works for resale or redistribution to servers or lists, or to reuse any copyrighted component of this work in other works must be obtained from the IEEE. 


\section{Organizational Assimilation of Collaborative Information Technologies: Global Comparisons}

\author{
Deepinder S. Bajwa \\ Western Washington University, Bellingham \\ Deepinder.bajwa@wwu.edu \\ Graham Pervan \\ Curtin University, Perth, Australia \\ Graham.pervan@cbs.curtin.edu.au \\ Bjorn E. Munkvold \\ Agder University College, Norway \\ Bjorn.e.munkvold@hia.no
}

\author{
L. Floyd Lewis \\ Western Washington University, Bellingham \\ Floyd.lewis@wwu.edu \\ Vincent Lai \\ The Chinese University of Hong Kong \\ Sklai@baf.msmail.cuhk.edu.hk \\ Gerhard Schwabe \\ University of Zurich, Switzerland \\ Swchwabe@ifi.unizh.ch
}

\begin{abstract}
This paper reports on a global initiative to investigate the assimilation of collaborative information technologies (CITs) in task-oriented collaboration. The two classes of CITs explored include conferencing and groupware technologies. Based upon the level of technology access/availability and utilization, four assimilation states are identified. Data collected from 538 organizations in the US, Australia, Hong Kong, Norway, and Switzerland is mapped in the four CIT assimilation states. The results indicate that the assimilation patterns of conferencing and groupware technologies vary across the study regions. Overall analyses of the organizational antecedents of CIT assimilation indicate that function integration and promotion of collaboration are significantly associated with the assimilation of conferencing and groupware technologies. Organization size and information technology (IT) function size, on the other hand, were found to be significantly associated only with the assimilation of conferencing technologies. Implications of our findings are discussed for practice and research.
\end{abstract}

\section{Introduction}

Collaboration to accomplish tasks is critical in modern organizations. As the information technology (IT) tools to support groups continue to emerge and become available to end-users, we are likely to witness an increasing emphasis on collaboration and virtualization of work. Most work teams are not only expected to collaborate within the enterprise but also with entities outside their organizational boundaries, including their value chain partners.

This increasing emphasis on collaboration (intra and/or inter-organization, virtual and/or face-to-face, synchronous and/or asynchronous) coupled with the availability of IT tools to support collaboration has spawned many investigations from practitioners and academic researchers. However, the majority of these endeavours (at least in the IT literature) have focused on individuals and groups engaged in collaboration. Organization level investigations have been scarce, especially those focusing on regional comparisons of diffusion of collaborative tools.

In this paper, we report on a global investigation to explore the assimilation of collaborative information technologies (CITs) at the organization level in the US, Australia, Hong Kong, Norway, and Switzerland. Unlike previous organization level studies that have focused on a limited subset of IT tools to support collaboration in a specific region of the globe, our study extends prior research by having a broader focus.

The next section provides a brief background of CITs. We then describe the theoretical premise underlying our research and the methodology of our global study. This is followed by data analyses and results of our findings. In the last section, we discuss our results and conclude with implications for future practice and research. 


\section{CIT Background}

IT attributes as organizational variables have been widely researched. Approaches conceptualizing IT as an organization variable have often varied with the objectives of research investigations. In our study, we use a categorical approach of conceptualizing IT since it has the advantage of focusing on a specific IT category/attribute under investigation [19]. This approach has been popular in many research studies. For example, several studies have examined Enterprise Resource Planning (ERP) systems (for a review see [6]), Group Support Systems (GSS) (for review of past studies see [7][8]), Decision Support Systems (DSS) (for a recent review of studies see [1]) etc. Other common IT categories identified include, amongst others: Knowledge Work Systems (KWS), Experts Systems (ES), and Collaborative Systems. Our research focuses on this last category of systems. We refer to Collaborative Systems as Collaborative Information Technologies (CITs) and explore many ITs that have the capability to support different types of collaborative environments.

Traditional IT support for collaboration was designed to improve performance of group members or teams by supporting communications, interactions, and the flow of information. However, modern day CITs have the capabilities not only to provide traditional support but also to support the computing needs of teams or groups engaged in accomplishing tasks or working on projects in different time/place scenarios.

Several ITs can support collaboration. While some of these have been around for decades (for example, telephone or audio conferencing, video conferencing, proprietary groupware, group support systems etc.), others have become more popular in the recent years primarily due to the commercialization of the Internet (for example, email, intranets, extranets, web conferencing, dataconferencing etc.). Today many vendors even offer integrated e-collaboration tools to support collaborative efforts [18].

\section{Research Framework}

Many theories have been applied to study the proliferation of CITs by researchers. Daft and Lengel [4] used "media richness" theory to explain how the "leanness" of different media plays an important role in selecting a collaborative technology for different types of tasks. Carlson and Davis [3] used "social interaction" to explain the choice of collaborative technology used by managers.
Other theories applied to study the impact of technology on collaborative tasks include: "social presence" theory [22], "media synchronicity" theory [5], and "communicative action" theory [14].

In our research, we deploy "innovation diffusion" theory to investigate CIT assimilation. Prior investigations of classes or clusters of technologies have often tapped on innovation theory to explain diffusion behaviour [11][13]. Moreover, innovation theory has been a popular premise to investigate diffusion of ITs [9].

In general, organization innovation is viewed as a stage model of initiation, adoption, and implementation [20]. Others view IT diffusion broadly as an assimilation process that involves initial innovation acquisition and deployment [10]. The focus of our study is on these two extreme activities in innovation assimilation, namely: innovation acquisition (availability) and innovation deployment (utilization). This perspective allows innovation assimilation to be investigated as combinations of varying levels of IT availability and utilization in organizations [17].

Specifically, our perspective implies that the assimilation of IT in an organization can lead to different "end states" or "transitional states" as IT innovations are acquired and deployed. For example, an IT can be widely adopted (i.e. accessible to a large proportion of end-users in the organization), but it may only be partially utilized. This could be the result of an assimilation gap [10], or the lag time between an IT's initial deployment and widespread use. Some innovations are also not adopted for widespread use throughout the organization but for a focused group of end-users who may utilize the adopted IT frequently (for example, CAD, CAM, etc.). Thus, even when IT adoption may be low from the organization level standpoint (i.e. accessible/ available to a fewer proportion of end users), it may have high utilization patterns.

Therefore, depending upon the level of IT accessibility/availability to organizational end-users, and its level of utilization by those end-users, four different "states" of IT assimilation may result (for illustration, we consider only two levels, low or high, of IT availability and utilization). These include: 1] Limited Assimilation (low availability/access and low utilization of an IT), 2] Focused Assimilation (low availability/access but high IT utilization), 3] Pervasive Assimilation (high IT access and utilization), and 4] Lagging Assimilation (high IT access/availability and low utilization of IT) (for a discussion of these states, see [17]). Figure 1 shows the basic conceptualization of IT assimilation "states". 


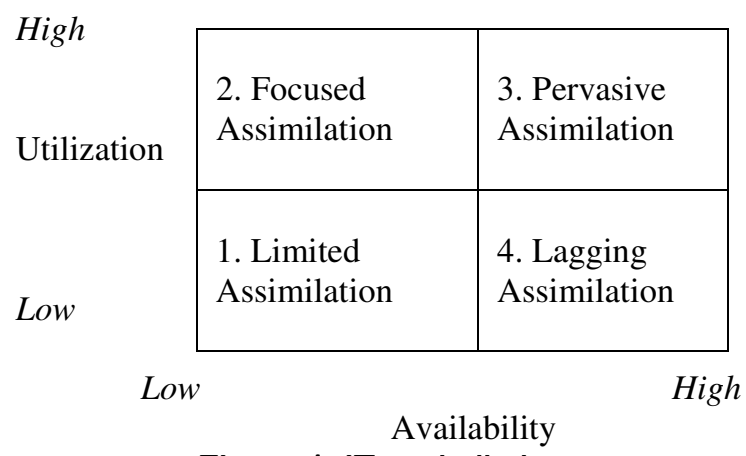

Figure 1. IT assimilation states

While the above framework does not capture the transition of IT from one state to another, it is useful in assessing the current assimilation state of an IT under investigation.

From a prediction standpoint, many factors can influence IT assimilation or diffusion behavior. According to Kwon and Zmud [16], these fall under the following categories: individual, task, innovation specific, structural, and environmental. However, as noted by Grover and Goslar [13], not all of them may be able to appropriately predict innovative behavior of multiple technologies considered collectively at the organization level. Moreover, many IT innovation studies in the past have provided inconclusive or contradictory results of innovation predictors. Conclusive results are more likely to be found when only those variables that are specific to the IT under investigation are included in the study [9].

From organization level assimilation of CIT standpoint, our study identified four variables that are likely to influence assimilation. These include: decision making patterns, functional integration, promotion of collaboration, and size-related (IT and organization) variables.

The impact of decision making pattern and functional integration on innovative behavior has been specifically addressed by Grover et al. [13]. Decentralized decision making patterns promote the proliferation of innovations. However, decentralized units require greater functional integration and therefore need more extensive communications to coordinate activities. This could perhaps be accomplished by CITs.

Promotion of collaboration by top echelons in the organization can also facilitate CIT assimilation. The arguments logically extend from the widely accepted notion than top management support, in terms of their participation and commitment is critical in the implementation of IT initiatives [15]. Finally, organization size as an antecedent of IT diffusion has been widely investigated. While the rationale points to the fact that larger, resource rich organizations are most likely to afford the cost of innovations, the results from some IT studies have been mixed (for a review see [2]). In the context of CITs, size (organization and IT function) may not be a significant predictor of adoption of some inexpensive CITs like email, audio conferencing, and some readily available web-based tools. On the other hand, size may significantly predict adoption and proliferation of relative more complex and expensive CITs like proprietary groupware and electronic meeting systems that also require significant amount of technical support. As for CIT utilization, larger firms may use various tools to a greater extent given their more geographically dispersed nature, the complexity of their tasks, and the need for greater coordination and control.

Although we have provided a rationale for the inclusion of our study variables in our research framework and may even have argued briefly for directional associations, our intent here is not to test any hypotheses, but instead to investigate whether the organizational predictors do differ given the CIT assimilation patterns in the five global regions.

The CITs considered in the present study included: email, teleconferencing (audio), video conferencing (two-way audio and video), dataconferencing (whiteboards, application sharing, data presentations), web-based tools (Intranets, Listservs, Newsgroups, chat, message boards), proprietary groupware tools (with or without web browser), and electronic meeting systems. While quite a few other tools to support collaboration have emerged since this study was initiated, the CITs for our study were identified after a review of the literature at the time of initiation of our research.

\section{Study Methodology}

A survey research design was deemed appropriate to investigate CIT assimilation. The instrument development approach suggested by Sethi and King [21] was deployed to ensure valid and reliable measures. We first conducted a thorough review of the literature to identify studies where variables similar to the ones included in our study had been operationalized. To the extent possible, we adopted the same item measures for our study variables. In some cases, we developed our own item measures after reviewing the academic and practitioner literatures. The instrument was then pilot tested using two experts, an executive director of the Society for Information Management [SIM] and a past CIO of a fortune 100 organization. Both were required to provide critical and detailed feedback which was then used to make modifications to produce the final instrument. 


\subsection{Measures}

Availability for each CIT cluster was measured by requiring respondents to indicate the proportion of endusers to whom the specific CIT cluster was "accessible and available" in their organization. A five-point scale semantically anchored at the extremes and mid-way ( $1=$ no one in the organization, $3=$ some persons in the organization, and $5=$ everyone in the organization) was used for each of the seven CIT clusters. Utilization was measured by asking the respondents to indicate the extent to which a CIT is currently being used to support task-oriented group collaboration in their organization. A five-point scale semantically anchored at the extremes and mid-way ( $1=$ never, $3=$ occasionally, $5=$ always) was deployed for each of the seven CITs.

Decision-making pattern in the organization was measured by using the six-item measure validated by Grover et al. [13]. These items focused on centralization or decentralization of major decisions involving capital budgets, new product/service introduction, entry into major new markets, pricing of major product lines, methods of personnel selection, and work methods to be used. A five-point scale semantically anchored at the extremes and mid-way ( $1=$ very decentralized decisions, $3=$ mixed, 5=very centralized decisions) was used for each item.

Degree of functional integration was also measured by using a five-item measure validated by Grover et al. [13]. These items focused on joint project development, application sharing, exchange of ideas, information sharing, and project initiations through joint interaction between departments. A five-point likert type scale ( $1=$ strongly disagree, $2=$ disagree, $3=$ neutral, $4=$ agree, $5=$ strongly agree) was used for each item.

Promotion of collaboration was measured by using a four item measure focusing on top management's active promotion of intra-organization collaboration, promotion of inter-organization collaboration, increasing use of virtual teams, and presence of specific person in the organization with the responsibility to manage and promote collaboration. A five-point likert type scale ( $1=$ strongly disagree, $2=$ disagree, $3=$ =neutral, $4=$ agree, $5=$ strongly agree) was used for each item.

Finally, size-related variables were measured using number of employees. For organization size, six categories of number of employees (less than 100, 100499, 500-999, 1,000-4,999, 5,000-10,000, and more than 10,000) were identified. For IT size, six categories of total number of IT employees (less than 10, 10-49, $50-99,100-499,500-1,000$, and more than 1,000) were identified.

\subsection{Data Collection}

Data collection for this research initiative was undertaken in five stages spanning a four year period. In the first stage, data was collected in the US in 2001 from member organizations of SIM. A web-based approach was used instead of mailing the instrument directly to members of SIM. An email explaining the broad objective of the research and a link to the survey web-site was sent to all members of SIM (approximately 1200 organizations at the time of the study). Specific instructions were provided on the survey to consider the CITs only in the context of their support in task-oriented collaboration, as opposed to their generic use for communications. We also requested that the survey be forwarded to the appropriate key executive/manager, if the recipient of the message was not knowledgeable about IT support for task-oriented collaboration. A reminder email was sent after 14 working days.

In the second stage, data was collected from organizations in Australia in 2002. A target sample of 500 randomly selected organizations from the Top 1000 was used to collect data using the same questionnaire that was administered in the US study. The survey was addressed to the most senior IT executive/manager in the organization. A brief cover letter and a reply-paid envelope were included in the package. Two mailings were undertaken over a period of two to three months. In the third stage, the study was extended to Hong Kong in 2002-2003. For the variables included in this paper, no modifications to item-measures were made. The subjects of the study were the MIS Directors of the largest four hundred and twenty companies in Hong Kong identified from the 2002 editions of Dun and Bradstreet Foreign Enterprises in Hong Kong and Dun and Bradstreet Key Enterprise in Hong Kong. Two rounds of mailings were undertaken over a period of four to five months. In the fourth stage, the study was extended to Norway in 2004. A random sample of 650 organizations was selected from the directory of the Norwegian Computer Society and data was collected using a web-based approach as done earlier in the US study. The survey was translated into Norwegian prior to data collection. Finally, in the fifth stage, the study was extended to Switzerland at the end of 2004 . The questionnaire (German translation) was sent to 1161 members of the Information and Communication Technology (ICT) in Switzerland. Swiss ICT is one of the prominent federations of the information and communication technology of Switzerland. Based upon the preference of the respondent in each organization, the questionnaire was either mailed or sent by email. 


\subsection{Response Profile}

We received five hundred and thirty eight usable responses from organizations in all the five countries. The individual response rates by country varied considerably. In general, they were lower for webbased surveys versus traditional mail surveys. Appropriate non-response bias checks were performed and no significant non-response biases were detected. Five hundred and thirty-one respondents indicated their position/title (table 1). These were classified into top tier (CIOs VPs CEOs, COOs, presidents, etc.), middle tier (general managers, knowledge officers, managers, directors, etc), and lower tier (supervisors, analysts, etc.). Table 2 shows the number of employees in our sample across all the five regions. While the percentage of organization size categories varied in each region, overall about $39 \%$ of our responding organizations had less than 500 employees, $43 \%$ of them had between 500 and 5000 employees, and 18\% had over 5000 employees. Table 3 shows the number of organizations and the percentage of all the organizations in each of the five regions that had adoption CITs. The overall adoption percentages indicate a sharp decrease in the adoption patterns of individual CITs. At the top end, almost $99 \%$ of the organizations in our sample had adopted email, $70 \%$ has adopted teleconferencing, and 56\% had adopted video conferencing. The sharp decline in overall adoption of teleconferencing and video conferencing can be attributed to their relatively low adoption rates in Norway and Switzerland as compared to the other three regions. At the bottom end, only about $29 \%$ of organizations had adopted electronic meeting systems (EMS) in the five regions.

Table 1. Respondent position profile

\begin{tabular}{lcclllr}
\hline Position & \multicolumn{3}{c}{ Country } & Total \\
\hline \multicolumn{1}{c}{ US } & Australia & Hong Kong & Norway & Switzerland \\
\hline Top Tier & $57[48 \%]$ & $26[18 \%]$ & $34[40 \%]$ & $38[52 \%]$ & $46[40 \%]$ & 201 \\
Middle Tier & $59[50 \%]$ & $106[76 \%]$ & $49[58 \%]$ & $15[21 \%]$ & $50[44 \%]$ & 279 \\
Lower Tier & $3[2 \%]$ & $8[6 \%]$ & $2[2 \%]$ & $20[27 \%]$ & $18[16 \%]$ & 51 \\
& & & & & 114 & 531 \\
Total & 119 & 140 & 85 & 73 & &
\end{tabular}

Table 2. Organization size of responding organizations

\begin{tabular}{llllllr}
\hline Employees & \multicolumn{3}{c}{ Country } & \multicolumn{2}{c}{ Total } \\
\hline & US & Australia & Hong Kong & Norway & Switzerland \\
\hline Less than 100 & $15[13 \%]$ & $11[8 \%]$ & $4[5 \%]$ & $34[43 \%]$ & $55[46 \%]$ & 119 \\
$100-499$ & $16[13 \%]$ & $20[14 \%]$ & $14[17 \%]$ & $19[25 \%]$ & $24[20 \%]$ & 93 \\
$500-999$ & $14[12 \%]$ & $31[22 \%]$ & $23[27 \%]$ & $10[13 \%]$ & $8[7 \%]$ & 86 \\
$1000-4999$ & $35[29 \%]$ & $59[42 \%]$ & $25[30 \%]$ & $10[13 \%]$ & $16[13 \%]$ & 145 \\
$5000-10,000$ & $7[6 \%]$ & $10[7 \%]$ & $10[12 \%]$ & $1[1 \%]$ & $2[2 \%]$ & 39 \\
$10,000+$ & $32[27 \%]$ & $9[6 \%]$ & $8[9 \%]$ & $1[1 \%]$ & $14[12 \%]$ & 64 \\
& & & & & & \\
Total & 119 & 140 & 84 & 75 & 119 & 537 \\
\hline
\end{tabular}

Table 3. Adoption of individual CITs

\begin{tabular}{|c|c|c|c|c|c|c|}
\hline$\overline{\text { CIT }}$ & & & Country & & & All \\
\hline & $\overline{\mathrm{US}}$ & Australia & Hong Kong & Norway & Switzerland & \\
\hline$\overline{\text { Email }}$ & $111[98 \%]$ & $116[98 \%]$ & $76[100 \%]$ & $64[99 \%]$ & $114[100 \%]$ & $481[99 \%]$ \\
\hline Tele (audio) & $105[93 \%]$ & $90[76 \%]$ & $60[80 \%]$ & $37[59 \%]$ & $41[37 \%]$ & $333[70 \%]$ \\
\hline Video & $86[76 \%]$ & $77[65 \%]$ & $52[69 \%]$ & $35[55 \%]$ & $19[17 \%]$ & $269[56 \%]$ \\
\hline P. groupware & $73[66 \%]$ & $73[62 \%]$ & $40[62 \%]$ & $18[30 \%]$ & $43[38 \%]$ & $247[53 \%]$ \\
\hline Dataconf. & $80[74 \%]$ & $48[42 \%]$ & $43[60 \%]$ & $25[40 \%]$ & $17[16 \%]$ & $213[46 \%]$ \\
\hline Web tools & $61[56 \%]$ & $43[39 \%]$ & $35[52 \%]$ & $20[32 \%]$ & $45[40 \%]$ & $204[44 \%]$ \\
\hline EMS & $42[38 \%]$ & $36[32 \%]$ & $21[33 \%]$ & $6[10 \%]$ & $27[24 \%]$ & $132[29 \%]$ \\
\hline
\end{tabular}




\section{Data Analyses}

For the purpose of this paper, we will focus on aggregate level of analysis. All the data were pooled together to assess the construct validity and reliability of our multi-item measures. We assessed the normality of pooled data and found most of the variable distributions to be normal. Principle component factor analysis was conducted on pooled data to assess the validity of all the items measuring decision making pattern, functional integration, and promotion of collaboration. All except two of the six items measuring decision making pattern loaded as expected. These two items (methods of personnel selection, and work methods to be used) were dropped for any further analysis and the principle component with varimax rotation was re-run. Although not reported here, all the items loaded on the three factors as expected. All the factor loadings exceeded 0.60 . The majority of the loadings ( 9 of the 13) were above 0.72 .

Access/availability and utilization/deployment scales for all the CITs were recoded from the original scales of 1-5 to 0-4. This was done for convenience so that a score of zero indicated no acquisition and deployment of the CIT under investigation. We next used the principle component factor analysis with varimax rotation on access/availability of all the seven CITs. The item measuring email adoption was excluded from the analysis since it loaded separately (perhaps due to its high accessibility in all the regions). The other six CITs loaded on two separate factors. Items measuring telephone/audio conferencing, video conferencing, and dataconferencing loaded on one factor (all loadings above 0.79) and the remaining three CITs (web-based tools, proprietary groupware, and electronic meeting systems) loaded on the second factor (loadings were all above 0.64). The two CIT cluster factors were labelled as "Conferencing CITs" and "Groupware CITs". Table 4 shows the descriptive statistics of the study variables with pooled data.

Overall, mean adoption of conferencing CITs is significantly higher than that for adoption of groupware CITs. This trend parallels that for utilization of conferencing and groupware CITs. To assess the assimilation of conferencing and groupware CITs, we mapped the two CIT categories in the IT assimilation framework shown in figure 1. For an organization to be mapped in the assimilation framework, the condition required a minimum score of 1 on both availability and utilization. For conferencing CITs, 337 organizations had a score of 1 or greater for their availability while 303 organizations had score of 1 or greater for their utilization. The cut-off point for low-high availability of conferencing CITs was a score of 6 (the midpoint of the conferencing CITs range from 1 to 12). This cut-off score resulted in $238(71 \%)$ of the organizations being classified as having "low" availability of conferencing CITs and the remaining $99(29 \%)$ organizations as having "high" availability of conferencing CITs.

A similar approach was used to determine cut-off point for low-high utilization of conferencing CITs. Analysis of data from 303 organizations resulted in a cut-off score of 5 (since the scores ranged from 1 to 10 , even though the actual range was 1-12.) between low and high groups. This cut-off score resulted in 206 (68\%) organizations being classified as having "low" utilization of conferencing CITs and the remaining 97 (32\%) organizations as having "high" utilization of conferencing CITs. Figure 2 shows the pattern of assimilation (availability and utilization) of conferencing CITs using our framework.

Table 4. Descriptive statistics

\begin{tabular}{llllll}
\hline Variables & $\mathrm{N}$ & Range & Mean & SD & Alpha \\
\hline Decision-making pattern & 532 & $1-5$ & 3.73 & 0.96 & 0.82 \\
Function integration & 530 & $1-5$ & 3.83 & 0.75 & 0.81 \\
Promotion of collaboration & 531 & $1-5$ & 3.25 & 0.81 & 0.70 \\
Adoption of conferencing CITs & 458 & $0-12$ & 3.81 & 3.40 & \\
Adoption of groupware CITs & 440 & $0-12$ & 2.95 & 2.76 & \\
Utilization of conferencing CITs & 437 & $0-12$ & 2.91 & 2.73 & \\
Utilization of groupware CITs & 412 & $0-12$ & 2.49 & 2.42 & \\
\hline
\end{tabular}


Proceedings of the 40th Hawaii International Conference on System Sciences - 2007

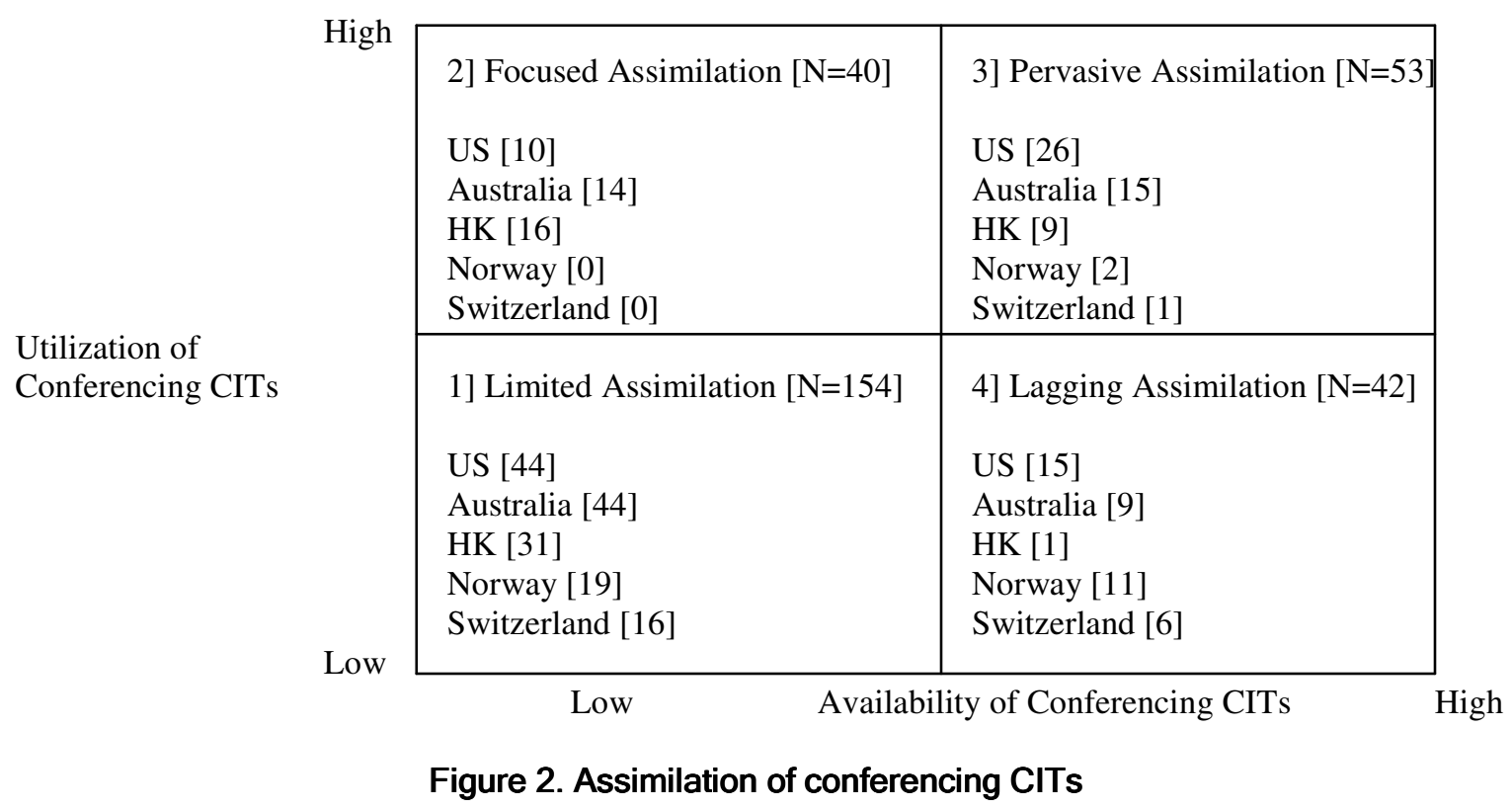

A total of 289 organizations in our sample were mapped using the framework (these indicated at least a score of 1 on both availability and utilization of conferencing CITs). Regional representation included $95(33 \%)$ organizations from the US, $82(28 \%)$ from Australia, 57 (20\%) from Hong Kong, 32 (11\%) from Norway, and only $23(8 \%)$ from Switzerland.

Overall, $154(53 \%)$ of the organizations were mapped in the "Limited Assimilation" quadrant, 40 (14\%) in "Focused Assimilation," 53 (18\%) in "Pervasive Assimilation," and $42(15 \%)$ in "Lagging Assimilation." Since, our focus is on aggregate level analyses, we conducted a one-way ANOVA between the four assimilation quadrants using decision-making pattern, functional integration, and promotion of collaboration as dependent variables. Table 5 shows the variable means in the four assimilation quadrants. Significance levels as detected by ANOVA are also indicated.

The effects of size-related variables were investigated using independent $\mathrm{t}$-tests between the two extreme assimilation quadrants (i.e. limited and pervasive assimilation). Although not reported in the table, both the size related variables means were significantly different (positive direction with significance at $\mathrm{p}<0.05$ ) between the limited and pervasive assimilation of conferencing CITs.

For groupware CITs, a similar mapping approach described for conferencing CITs was used. Three hundred and one organizations had a score of 1 or greater for availability while 278 organizations had score of 1 or greater for the utilization of groupware CITs. Analysis of data from 301 organizations resulted in a cut-off score of 6 between low and high groups. This cut-off score resulted in 255 (85\%) of the organization being classified as having "low" availability of groupware CITs and the remaining 46 $(15 \%)$ organizations as having "high" availability of groupware CITs. As for low-high utilization of groupware CITs, analysis of data from 278 organizations resulted in a cut-off score of 5 (since the scores ranged from 1 through 10 , even though the actual range was 1-12). This cut-off score resulted in $216(78 \%)$ organizations being classified as having "low" utilization and the remaining 62 (22\%) organizations as having "high" utilization of groupware CITs.

Figure 3 shows the pattern of assimilation (availability and utilization) of groupware CITs using our framework. A total of 263 organizations in our sample were mapped using the framework. Regional representation included $76(29 \%)$ organizations from the US, 62 (24\%) from Australia, 44 (17\%) from Hong Kong, only 22 (8\%) from Norway, and 59 (22\%) from Switzerland. Overall, 190 (72\%) organizations were mapped in the "Limited Assimilation" quadrant, 29 $(11 \%)$ in "Focused Assimilation," 31 (12\%) in "Pervasive Assimilation", and only 13 (5\%) in "Lagging Assimilation." One-way ANOVA results between the four assimilation quadrants using decision-making pattern, functional integration, and promotion of collaboration as dependent variables are shown in table 6. No size-related effects were detected when independent $\mathrm{t}$-tests were conducted between the two extreme assimilation quadrants (i.e. limited and pervasive assimilation). 
Table 5. Descriptive statistics of variables in assimilation quadrants for conferencing CITs

\begin{tabular}{|c|c|c|c|c|c|}
\hline \multirow[t]{2}{*}{ Variables } & \multirow[t]{2}{*}{ Descriptives } & \multicolumn{4}{|c|}{ 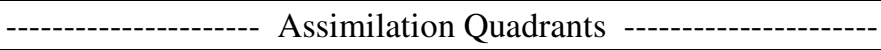 } \\
\hline & & Limited & Focused & Pervasive & Lagging \\
\hline \multirow{2}{*}{ Decision-making pattern } & Mean & 3.71 & 3.88 & 3.46 & 3.60 \\
\hline & SD & 0.91 & 0.97 & 1.09 & 1.05 \\
\hline \multirow[t]{2}{*}{ Functional integration* } & Mean & 3.81 & 3.92 & 4.12 & 3.96 \\
\hline & SD & 0.78 & 0.73 & 0.71 & 0.79 \\
\hline \multirow[t]{2}{*}{ Promotion of collaboration $* * *$} & Mean & 3.20 & 3.43 & 3.77 & 3.58 \\
\hline & SD & 0.78 & 0.68 & 0.75 & 0.70 \\
\hline
\end{tabular}

$* \mathrm{p}<0.10 \quad * * * \mathrm{p}<0.005$

\begin{tabular}{|l|l|l|}
\cline { 2 - 3 } & 2] Focused Assimilation [N=29] & 3]Pervasive Assimilation [N=31] \\
& US [9] \\
US [9] & Australia [14] \\
Australia [6] & HK [3] \\
NK [8] & Norway [2] \\
Switzerland [3]
\end{tabular}

Figure 3. Assimilation of groupware CITs

Table 6. Descriptive statistics of variables in assimilation quadrants for groupware CITs

\begin{tabular}{llllll}
\hline Variables & Descriptives & \multicolumn{4}{l}{ Assimilation Quadrants } \\
\hline & & Limited & Focused & Pervasive & Lagging \\
\hline \multirow{2}{*}{ Decision-making pattern } & Mean & 3.69 & 3.52 & 3.97 & 3.51 \\
& SD & 0.99 & 0.98 & 0.83 & 0.79 \\
& & & & & \\
Functional integration* & Mean & 3.88 & 4.15 & 4.17 & 4.08 \\
& SD & 0.69 & 0.70 & 0.75 & 0.83 \\
Promotion of collaboration*** & Mean & 3.33 & 3.60 & 3.84 & 3.38 \\
& SD & 0.78 & 0.75 & 0.79 & 0.97 \\
\hline
\end{tabular}

$* \mathrm{p}<0.10 \quad * * * \mathrm{p}<0.005$ 


\section{Discussion and Conclusions}

From conferencing CITs standpoint, the majority of the organizations in our global sample have "Limited Assimilation". As for "Pervasive Assimilation" of conferencing CITs, it is almost nonexisting in Norway and Switzerland. There were also no organizations from Norway and Switzerland that were classified in "Focused Assimilation" of conferencing CITs. This could possibly be attributed to relatively smaller organization sizes in Norway for whom the costs of using these CITs (especially video conferencing) can be a significant barrier.

As for the assimilation of groupware CITs, a high majority of the organizations in our sample (72\%) were classified in "Limited Assimilation" quadrant. Very few organizations (5\%) were classified in the "Lagging Assimilation" quadrant, suggesting that when these CITs are made highly available, most organizations tend to use them frequently. In fact there were no organizations in Hong Kong that were classified in this quadrant. As a norm for most organizations in Hong Kong, IT acquisition (over a certain budget) needs to be justified prior to purchase and evaluated after its implementation. The department(s) making inappropriate acquisitions may be monitored, which subsequently may limit their IT budget and spending in the future but at the same time promote high utilization once groupware CITs are made organizationally wide available.

We also found that greater functional integration, higher promotion of collaboration, larger organizations and IT functions are associated with proliferation of conferencing CITs from "Limited" to "Pervasive" assimilation. While the first two variables also appear to have a similar influence on the assimilation of groupware technologies, size-related variables were not found to have any significant influence on progression of assimilation of groupware CITs. While this is somewhat surprising, it must be noted that the majority of the web-based tools are relatively inexpensive, fairly easy to acquire and maintain, and very user friendly. We did find that more organizations in Norway and Switzerland had adopted web-based tools than proprietary groupware and EMS. Perhaps this could explain the lack of influence of organization size on assimilation of groupware CITs. It is also possible that the groupware CITs included in this study may not be supported by centralized IT functions and may in fact, have their own dedicated technical support staff that may not officially belong to the organization's IT function.

Our study has important implications for practice and research. From the practitioner standpoint, our results provide benchmarks to evaluate assimilation of
CITs. "Limited Assimilation" of CITs could be a result of low levels of functional integration and little promotion of collaboration by top management. If organizational environments dictate greater integration, then collaboration must be promoted to encourage the proliferation of CITs. When assimilation of CITs is "Focused", executives need to evaluate the organizational usefulness of these CITs and accordingly assess their fate for pervasiveness. It is plausible that some CITs may only be useful for focal group of end-users. In such cases, attempts to make the CIT pervasive by promoting collaboration may result in wasted resources. Finally, "Lagging Assimilation" of CITs is perhaps a situation that demands special attention. Typically, this could be a result of not only lack of promotion of collaboration but also of lack awareness of availability of CITs. Fostering the promotion of collaboration along with end-user awareness, education, and training could assist in elevating lagging CITs to pervasive state.

From a research standpoint, this study informs about the state of assimilation of CITs in five global regions. Despite the increased popularity of IT enabled collaboration in modern organizations, our findings convey a conservative global picture. Many questions still remain unanswered. For example, what other factors influence organization wide adoption and frequent utilization of CITs? What collaborative tasks are these CITs being assimilated for? What other CITs are being assimilated to support collaboration?

Given the "transient nature" of collaborative tools, new technologies present alternative channels for collaboration. The integration of services within webbased tools also represents complicating factors here along with the recent "bundling" of collaboration functionality in standard software from Microsoft. Therefore, rather than investigating specific CITs, future research efforts may need to be directed at exploring functionality that is being acquired and utilized to support collaborative efforts.

While our study fills an important void in the literature, we also recognize the limitations of our research. First, a single informant from each organization was required to complete the survey. Second, our study captures specific assimilation states in the "global assimilation" of CITs with data collected over a period of four years. A more compressed data collection period would have provided a more accurate and realistic profile of assimilation patterns of CITs. Finally, undertaking global surveys using validated measures from a single region (US in our research) can cause concerns in aggregate level analysis. However, despite these limitations, our research furthers understanding of assimilation of CITs in selected global regions. 


\section{References}

[1] Arnott, D., \& Pervan, G. (2005). A critical analysis of decision support systems research. Journal of Information Technology, 20 (2), 67-87.

[2] Bajwa, D.S. \& Lewis, L.F. (2003). Does size matter? An investigation of collaborative information technology adoption by US firms. Journal of Information Technology Theory and Practice, 5(1), 2946.

[3] Carlson, P.J. \& G. B. Davis. (1998). An investigation of media selection among directors and managers: From "self" to "other" orientation. MIS Quarterly, 22(3), 335-362.

[4] Daft, R. and Lengel, R. (1986). Organization information requirements, media richness, and structure design. Management Science, 32(5), 554-571.

[5] Dennis, A.R., Valacich, J., Speier, C, \& Morris, M. (1998). Beyond media richness: An empirical test of media synchronicity theory. Proceedings of the Hawaii International Conference on System Sciences, 48-57, Maui.

[6] Esteves, J. and Pastor, J. (2001). Enterprise resource planning systems research: An annotated bibliography, Communications of the Association for Information Systems, 7, Article 8.

[7] Fjermestad, J. and Hiltz, S.R. (2001). Group support systems: A descriptive evaluation of case and field studies. Journal of Management Information Systems, 17(3), 115-159.

[8] Fjermestad, J. and Hiltz, S.R. (1999). An assessment of group support systems experimental research: Methodology and results. Journal of Management Information Systems, 15(3), 7-149.

[9] Fichman, R. G. (1992). Information technology diffusion: A review of empirical research. Proceedings of the Thirteenth International Conference on Information Systems (ICIS).

[10] Fichman, R. G. \& C.F. Kemerer. (1999). The illusory diffusion of innovation: An examination of assimilation gaps. Information Systems Research, 10(3), 255-275.

[11] Gallivan, M.J. (2001). Organizational adoption and assimilation of complex technology innovations: Development and application of a new framework. The
DATA BASE for Advances in Information Systems, 32(3), 52-85.

[12] Grover V, Fiedler, K. D., and Teng, J. T. (1999). The role of organizational and information technology antecedents in reengineering initiation behaviour. Decision Sciences, 30(3), 749-781.

[13] Grover, V. and M. D. Goslar. (1993). The initiation, adoption, and implementation of telecommunications technology in the U.S. Journal of Management Information Systems 10(1), 141-163.

[14] Habermas, J. (1984). The Theory of Communicative Action: Reason and Rationalisation of Society. Beacon Press: Boston, MA.

[15] Jarvenpaa, S.L. and Ives, B. (1991). Executive involvement and participation in the management of information technology. MIS Quarterly, 15(2), 204224.

[16] Kwon, T. H., and Zmud, R. W. (1987) Unifying the fragmented models of information systems implementation. In R.J. Boland and R.A. Hirschheim (eds.), Critical Issues in Information Systems Research (New York: John Wiley).

[17] Lewis, L.F., Bajwa, D., \& Pervan, G. (2004). An empirical assessment patterns and the benefits of collaborative information technologies. Journal of Computer Information Systems, 44(4), 16-26.

[18] Munkvold, B.E. \& Zigurs, I. (April-June 2005). Integration of e-collaboration technologies: Research opportunities and challenges. International Journal of e-Collaboration, 1(2), 1-24.

[19] Robey, D. (1981). Computer information systems and organization structure. Communications of ACM, 24, 679-687.

[20] Rogers, E.M. (1983). Diffusion of Innovations. 3rd ed. The Free Press, New York.

[21] Sethi, V. and King, W.R. (1991). Construct measurement in information systems research: An illustration in strategic systems. Decision Sciences, 22(3), 455-472.

[22] Short, J.E., Williams, E., \& Christie, B. (1976). The Psychology of Communications. London: John Wiley. 